\title{
FENOLOGIA E GERMINAÇÃO DE SEMENTES DE AGUAI, Chrysophyllum gonocarpum (Mart. \& Eichl.) Engl.
}

\author{
Marciele Felippi*, Fernando Grossi**, Antonio Carlos Nogueira**, Yoshiko Saito Kuniyoshi*** \\ *Bióloga, M.Sc. - marciele.f@terra.com.br \\ **Eng. Florestal, Dr., Depto. de Ciências Florestais, UFPR - f_grossi@ufpr.br - nogueira@.ufpr.br \\ ***Naturalista, Dr ${ }^{\mathrm{a}}$., Depto. de Ciências Florestais, UFPR - yoshiko@ufpr.br
}

Recebido para publicação: 22/06/2007 - Aceito para publicação: 19/09/2007

\begin{abstract}
Resumo
Informações básicas sobre Chrysophyllum gonocarpum (Mart. \& Eichl.) Engl., Sapotaceae, ainda são incipientes. Assim, pretende-se contribuir com dados fenológicos, morfológicos e germinativos sobre essa espécie. As observações e a coleta de material botânico foram realizadas na região do Médio Alto Uruguai e das Missões (RS), de setembro de 2004 a novembro de 2005, e os testes físicos e germinativos em laboratório. A espécie floresce de setembro a dezembro, e frutifica de maio a novembro. A inflorescência é constituída por grupos de pequenas flores branco-esverdeadas com prefloração imbricada, sendo a flor metaclamídea, actinomorfa, pentâmera, com gineceu sincárpico, súpero, anteras extrorsas, rimosas, dorsifixas e placentação axilar. O fruto é uma baga quadrangular, com epicarpo liso, de cor amarela, de mesocarpo e endocarpo carnoso macio, ovário com 1 a 5 sementes em forma de meia lua, tegumento lustroso, de cor castanha, com cicatriz linear visível. O embrião possui dois cotilédones grandes, foliáceos, hipocótilo curto e espesso, endosperma uniforme, circundando o embrião. A germinação é epígea e a plântula é caracterizada como fanerocotiledonar. $\mathrm{Na}$ análise física, o peso de 1000 sementes foi de $381 \mathrm{~g}$, contabilizando 2.625 unidades por quilo, com umidade de 47,16\%. Quanto à germinação, os resultados obtidos apontaram para um processo lento e desuniforme, demonstrando, portanto, a necessidade de maiores estudos para acelerar, uniformizar ou até mesmo estabelecer a germinação.

Palavras-chave: Chrysophyllum gonocarpum; fenologia; morfologia; germinação.
\end{abstract}

\begin{abstract}
Phenology and seeds germination of Chrysophyllum gonocarpum (Mart. \& Eichl.) Engl. Basic information on Chrysophyllum gonocarpum, Sapotaceae, still is incipient, therefore, this study intends to contribute with phenology, morphologic and germination registers. Comments and collection of botanical material had been carried out in the Region of the High Medium Uruguay and Missions (RS), from September/2004 to November/2005, as well as the physical and germination tests in laboratory. The species iniates flowers and blooms from September to December and the fruits from May to November. The inflorescence is constituted by groups of small flowers white-greenish with imbricate prebudding, being the metachlamydae, actinomorphic, pentamerous flower, with, upper syncarpus gymnoecium, anthers extrorse, distinct usuably dithecal opening by longitudinal slits, dorsifixix and axillary placentation. The fruit is a quadrangular berry of yellow colour, smooth surface, fleshy mesocarp and endocarp; from 1 to 5 seeds, luniformin moon form half with tegument of brown colour, bright thin pulp, with visible linear scar. The embryo posses two great large foliaceous cotyledons, hipocotylilo short and thick, endosperm uniform, surrounding the embryo. The germination is epigeal and the and seedling is phanerocotylar. The weight of 1,000 seeds is $381 \mathrm{~g}$ with 2,625 units per $\mathrm{kg}$, with humidity of $47.16 \%$. The results pointed out that the germination is slow desuniforme and therefore there is need for more studies to accelerate, uniform or even establish the germination.

Keywords: Chrysophyllum gonocarpum; phenology; morphology; germination.
\end{abstract}

\section{INTRODUÇÃO}

Chrysophyllum gonocarpum (Mart. \& Eichl.) Engl., Sapotaceae, conhecida como aguai, é uma espécie arbórea de 6-20 m de altura, podendo alcançar até $60 \mathrm{~cm}$ de diâmetro (REITZ, 1968). Possui copa 
densa, verde-escura, flabeliforme, com numerosos galhos finos. Os galhos novos possuem ritidoma estrigoso pubescente, casca interna com exsudação de látex leitoso, também verificada em suas folhas quando feridas (MARCHIORI, 2000). A espécie é da fase sucessional secundária tardia ou clímax, estando presente em grande número no estrato intermediário e inferior (KUERA et al., 2002; LORENZI, 2002). Por sua importância paisagística, econômica e ecológica, é indicada para recuperação de áreas degradadas (REITZ, 1968; LORENZI, 2002). No Brasil, além do Nordeste, a espécie ocorre no Rio de Janeiro, em Minas Gerais, até o Rio Grande do Sul, em Floresta Estacional Semidecidual. É freqüente na depressão central do Rio Grande do Sul, rio Uruguai, sobretudo nos capões dos campos (REITZ, 1968; LORENZI, 2002; LONGHI, 1995). Produz anualmente grande quantidade de sementes, sendo de 1 a 5 por fruto (REITZ, 1968; PENNINGTON, 1968; KUERA et al., 2002). Conforme Lorenzi (2002), a viabilidade das sementes persiste por mais de seis meses, sendo que a germinação é moderada, ocorrendo em 20-30 dias.

Com estudos fenológicos de uma espécie, pode-se avaliar a disponibilidade de recursos fornecidos por ela ao longo do ano (MORELLATO, 1995). Esse conhecimento pode ser aplicado em várias áreas de atuação, possibilitando determinar estratégias de coleta de sementes e disponibilidade de frutos, o que influenciará a qualidade e a quantidade da dispersão das sementes (MARIOT et al., 2003).

As informações fenológicas são valiosas do ponto de vista botânico, ecológico e silvicultural, e necessárias para apoiarem outros estudos, como os de fisiologia de sementes e até os de revisão taxonômica, possibilitando melhor compreensão sobre a biologia das espécies, indispensável para plantios ou para a condução de manejo florestal (ALENCAR, 1994).

O conhecimento das estruturas morfológicas de órgãos vegetais e plântulas é de suma importância para análises em laboratório, identificação, diferenciação de espécies, taxonomia e silvicultura (AMORIM, 1996). Essas estruturas podem fornecer indicações sobre armazenamento, viabilidade e métodos de semeadura (KUNIYOSHI, 1983). Da mesma forma, auxiliam na compreensão da dinâmica de populações vegetais, bem como no reconhecimento do estágio sucessional em que a floresta se encontra (OLIVEIRA, 1993; DONADIO; DEMATÊ, 2000).

Vários estudos sobre a morfologia de espécies nativas do Brasil têm sido desenvolvidos, como o de Barroso (1978), que analisou e descreveu as estruturas morfológicas externas e internas das sementes de várias famílias de dicotiledôneas e monocotiledôneas, definindo tipos de reserva do endosperma e classificando os embriões de acordo com as formas que ocupam no interior da semente. Kuniyoshi (1983) descreveu 25 espécies arbóreas da Floresta Ombrófila Mista, fornecendo características dos frutos, das sementes e do desenvolvimento das plântulas. Em continuidade a esse trabalho, Roderjan (1983) descreveu detalhadamente 24 espécies arbóreas, nos estágios de plântulas e mudas das mesmas espécies. Amorim (1996) descreveu morfologicamente o fruto, a semente, a germinação, a plântula e a muda de dez espécies florestais. Abreu (2002) caracterizou a morfologia de frutos, sementes e germinação de duas espécies arbóreas. Lopez (1999) estudou morfologicamente folhas, inflorescência e frutos das espécies de Diospyros Dalech. ex L. Souza et al. (2002) estudoram a morfoanatomia da flor de Guarea kunthiana A. Juss. e de Guarea macrophylla Vahl. (Meliaceae).

$\mathrm{O}$ estudo de métodos adequados em análises de sementes para as espécies florestais tem merecido atenção no meio científico, visando obter informações que exprimam a qualidade fisiológica da semente, tanto para sua preservação como para a utilização com os mais variados interesses. É de extrema importância estudar assuntos básicos, como o melhoramento da qualidade das sementes, para fins de comercialização (ALCALAY; AMARAL, 1981).

Poucos são os trabalhos relacionados à germinação de sementes da família Sapotaceae, podendo-se citar Matos et al. (2003) e Cruz; Carvalho (2003). Chrysophyllum gonocarpum possui importância paisagística, econômica e ecológica, porém faltam informações básicas sobre, principalmente, as características da germinação e da plântula.

Portanto, com o objetivo de utilizá-la para testes de germinação e produção de mudas, foram descritos neste trabalho alguns aspectos fenológicos e morfológicos externos e internos da flor, fruto e semente, assim como os aspectos externos do processo germinativo e da plântula, além dos testes germinativos e físicos das sementes de aguai.

\section{MATERIAL E MÉTODOS}

\section{Local de coleta}

O material botânico para o trabalho foi obtido no Município de Frederico Westphalen, Rio Grande do Sul, situado no Planalto Meridional Brasileiro, porção centro-norte do estado do Rio Grande 
do Sul, região denominada Alto Uruguai, a qual acompanha o arco formado pelo rio Uruguai.

A temperatura média anual situa-se em torno de $18^{\circ} \mathrm{C}$, e a precipitação média anual é elevada, geralmente entre 1.800 e $2.100 \mathrm{~mm}$ bem distribuídas ao longo do ano, embora, nos últimos anos, tenha havido períodos de seca (MISSIO, 2003).

Quanto ao solo, predominam Neossolo Litólico e Latossolo roxo (BRASIL, 1973). A cobertura florestal da região de estudo pertence ao domínio da Floresta Estacional Decidual, segundo o Inventário Florestal Contínuo do Rio Grande do Sul (2001).

\section{Seleção de matrizes e observação quanto aos aspectos fenológicos}

Foram selecionadas 10 matrizes, aparentemente sadias, com fuste reto, copa bem formada e com distância mínima de $20 \mathrm{~m}$ entre si.

Para caracterização de aspectos fenológicos, foram escolhidos aleatoriamente cinco galhos de cada uma das matrizes, sendo contabilizados 10 botões florais em cada ramo.

Durante o período de 72 horas, das cinco às $19 \mathrm{~h}$, foram observados o horário de abertura e fechamento das flores e a visita de polinizadores. Além disso, foram acrescidas informações registradas de dois anos anteriores a este trabalho, sobre época de floração e frutificação e os indivíduos responsáveis pela dispersão de sementes.

O período de observação quanto aos aspectos fenológicos e características morfológicas de Chrysophyllum gonocarpum foi realizado entre setembro de 2004 e novembro de 2005.

\section{Coleta de material botânico}

Foram coletadas flores em pré-antese e antese, e frutos em diferentes fases de desenvolvimento, das matrizes selecionadas. Inicialmente, os botões florais, flores e frutos foram conservados em álcool ( $70 \%)$, armazenados em frascos de vidro, à temperatura ambiente, no Laboratório de Sementes Florestais do curso de Engenharia Florestal da Universidade Federal do Paraná (UFPR), para posterior análise e ilustrações, que foram realizadas com auxílio de microscópio binocular estereoscópico e lupa de mesa.

Os frutos maduros foram coletados no mês de setembro de 2005 e foram macerados e despolpados em água corrente, para a extração das sementes. Estas foram misturadas e dessa mistura foram retiradas amostras para a determinação do peso de mil sementes, do número de sementes por quilo e do teor de água, assim como para os testes de flutuação, embebição e germinação, adotando-se as Regras de Análises de Sementes (BRASIL, 1992).

\section{Morfologia da flor}

Para a descrição das flores, foram coletados cinco exemplares aleatoriamente de cada matriz, e observados e descritos a gema floral, o cálice, a corola, o androceu e o gineceu. O procedimento metodológico para as observações e a terminologia empregada, assim como os parâmetros observados nas descrições, foi baseado nos trabalhos de Weberling (1989), Bell (1991), Agarez; Rizzini; Pereira (1994), Barroso et al. (1999), Vidal; Vidal (2000) e Souza (2003).

\section{Morfologia do fruto}

Para a descrição morfológica dos frutos, foram utilizados 200 exemplares selecionados dentre as dez matrizes, sendo frutos sadios, inteiros, sem deformação e maduros. Utilizou-se paquímetro mecânico $(1 / 50 \mathrm{~mm})$ para a medição do comprimento, da espessura e da largura, anotando-se os valores máximos e mínimos. Consideraram-se o comprimento, a distância entre a base e o ápice do fruto, a largura (o lado mais largo) e a espessura (o lado mais estreito). Com o auxílio de lupa de mesa, foram observados detalhes externos e internos do pericarpo, referentes à textura, consistência, pilosidade, brilho, forma e número de sementes por fruto. A metodologia e a terminologia empregada, assim como os parâmetros observados para as descrições, foram baseadas nos trabalhos de Barroso (1978), Kuniyoshi (1983), Feliciano (1989), Weberling (1989), Bell (1991), Agarez; Rizzini; Pereira (1994), Amorim (1996), Barroso et al. (1999) e Vidal; Vidal (2000).

\section{Morfologia da semente}

Para as medições de comprimento, largura e espessura das sementes, utilizou-se a mesma metodologia utilizada para os frutos. Além disso, foram obtidas secções transversais e longitudinais de 
100 exemplares coletados entre as matrizes selecionadas e, com auxílio de lupa de mesa, foram observadas as características externas, como a cor, a consistência, a forma, o contorno, a superfície da semente, a localização e tamanho da micrópila, a presença de rafe e de partes associadas e sua localização e tamanho, cor e forma do hilo. Quanto às características internas, observaram-se a presença ou ausência de endosperma, sua textura, consistência e coloração; quanto ao embrião, a posição, o tamanho e a forma do eixo embrionário; em relação aos cotilédones, a textura, a cor, a forma e a presença ou não de nervuras. A terminologia empregada e os parâmetros observados para as descrições basearam-se nos trabalhos de Barroso (1978), Weberling (1989), Feliciano (1989), Bell (1991), Agarez; Rizzini; Pereira (1994), Amorim (1996), Barroso et al. (1999), Vidal; Vidal (2000) e Souza (2003).

\section{Morfologia do processo germinativo até a plântula}

Para o acompanhamento das fases de germinação, foram colocadas sementes para germinar em substrato de rolo de papel-toalha umedecido com água destilada. Em seguida, foram levadas ao germinador, regulado à temperatura de $25^{\circ} \mathrm{C}$, na presença de luz constante. Foram utilizadas duas repetições de 20 sementes cada. A germinação foi considerada desde a emissão da radícula até a expansão dos protofilos. Foram utilizados exemplares bem desenvolvidos e representativos de cada fase, para as ilustrações.

O procedimento metodológico e a terminologia empregada seguiram os trabalhos de Barroso (1978), Kuniyoshi (1983), Roderjan (1983), Weberling (1989), Feliciano (1989), Bell (1991), Agarez; Rizzini; Pereira (1994), Amorim (1996), Barroso et al. (1999), Vidal; Vidal (2000) e Souza (2003).

\section{Análise física das sementes}

Para o teste de flutuação, foram utilizadas quatro repetições com 100 sementes cada, sendo colocadas em um recipiente com água para verificar a porcentagem de sementes flutuantes, as quais, posteriormente, foram abertas para visualização interior.

Para o peso de mil sementes, foram utilizadas oito repetições de 100 sementes cada uma, e calculado o coeficiente de variação. A determinação do teor de umidade para sementes verdes, maduras, após embebição e cinco e sete dias após a coleta foi obtida pelo método de estufa a $105{ }^{\circ} \mathrm{C} \pm 3{ }^{\circ} \mathrm{C}$ por 24 horas, usando-se 4 repetições com 10 sementes cada uma, de acordo com as Regras de Análises de Sementes (BRASIL, 1992). As sementes com as quais foi realizado o teste de umidade cinco e sete dias após a coleta ficaram em temperatura ambiente, à sombra.

O teste de embebição contou com dois tratamentos, sendo o primeiro com corte na região calazal da semente, e o segundo com sementes intactas. Utilizaram-se cinco repetições de vinte sementes cada uma, imersas em água destilada, durante três dias, na presença de luz branca, em germinador a $25^{\circ} \mathrm{C}$. Inicialmente, de hora em hora, durante um período de 12 horas, as sementes foram enxugadas com papel de filtro e pesadas em balança com precisão de 0,01 g. Após esse período, durante dois dias, com intervalo de 12 horas, foram pesadas novamente. Os resultados foram apresentados em porcentagem de aumento de peso, em relação ao peso da matéria fresca inicial.

\section{Testes de germinação}

Foram realizados testes preliminares de germinação, nos quais se observou a grande presença de fungos. Por esse fato, foram elaborados três tratamentos para diminuir os índices de contaminação e assim observar a germinação.

Adotaram-se três tratamentos com sete repetições de 25 sementes cada uma. No primeiro tratamento, as sementes passaram por cinco minutos de imersão em hipoclorito 3\% (PA). No segundo, houve lavagem das sementes, esfregando-as com areia e água, e dez minutos de imersão em hipoclorito comercial (2\%). No terceiro, foram dez minutos de imersão em hipoclorito 3\% (PA).

Após imersão em hipoclorito, as sementes permaneceram em uma peneira na água corrente por 20 minutos. Posteriormente, foram colocadas em caixas plásticas "gerbox", sendo utilizados 25 g de vermiculita média esterilizada e $85 \mathrm{ml}$ de água destilada, e introduzidas em germinador à temperatura de $25^{\circ} \mathrm{C}$. A umidade foi mantida adicionando-se água sempre que necessário.

A avaliação da germinação foi diária, sendo consideradas sementes germinadas as que apresentaram emissão de radícula, com no mínimo $2 \mathrm{~mm}$. Foram avaliados a porcentagem e o índice de velocidade de germinação. 


\section{Análise estatística}

Os testes de germinação foram conduzidos em delineamento inteiramente casualizado, no qual foram utilizados 3 tratamentos com 7 repetições de 25 sementes cada uma.

Para o cálculo de germinação, foi utilizado o índice de velocidade de germinação, empregandose a fórmula de Maguire, citado por Nakagawa (1994): IVG $=\mathrm{G} 1 / \mathrm{N} 1+\mathrm{G} 2 / \mathrm{N} 2+\ldots+\mathrm{Gn} / \mathrm{Nn}$, onde IVG é o índice de velocidade de germinação, G1, G2 ... Gn se referem ao número de sementes germinadas computadas na primeira contagem, na segunda contagem e na última contagem, e N1, N2 ... Nn se referem ao número de dias de semeadura na primeira, segunda e última contagem.

Para a porcentagem de germinação, efetuou-se a análise de variância e o teste de Tukey a 5\% para comparação das médias.

\section{RESULTADOS E DISCUSSÃO}

\section{Aspectos fenológicos}

De setembro a dezembro de 2004 e de 2005, observou-se uma abundante floração, sendo irregular, ou seja, não ocorre floração todos os anos, fato este comprovado com observações preliminares anteriores ao início do trabalho. O mesmo foi observado, conforme Alencar (1994), para outras espécies do gênero, como Chrysophyllum oppositum, com periodicidade anual irregular. Segundo Longhi (1995), a floração de C. gonocarpum ocorre de novembro a dezembro; e de outubro a fevereiro para Kuera et al. (2002). Também se observou neste estudo que, em ambientes secos, mesmo havendo floração, ocorre grande taxa de aborto das flores, ou seja, não se obtiveram frutos dessas matrizes, sendo estas mais sensíveis ao vento e chuva fortes.

A antese é diurna, iniciando a abertura pela manhã, entre seis e oito horas, sendo que as flores permanecem abertas por aproximadamente 24 horas. Após esse período, algumas flores murcharam e a corola desprendeu-se. Entretanto, outras caíram provavelmente devido à não-polinização ou por agentes externos, como vento e chuva fortes. A visitação é realizada por insetos, entre eles abelhas e formigas, com maior concentração de visitantes pela manhã e ao final da tarde. Quanto a esses aspectos, não há trabalhos na literatura, em se tratando da espécie C. gonocarpum.

\section{Morfologia da flor}

A inflorescência é constituída por grupos de pequenas flores branco-esverdeadas com prefloração imbricada. Nessa espécie, é possível encontrar frutos em desenvolvimento na base do eixo da inflorescência e flores abertas no ápice. As flores se originam no próprio caule (Figura 1A, B), fenômeno este conhecido como caulifloria. Flor metaclamídea, actinomorfa, pentâmera, dialissépala, simpétala (Figura 1C), gineceu sincárpico, súpero, plurilocular, com placentação axilar, estilete e ovário de forma oval (Figura 1D). Na base do ovário emergem pêlos de coloração branca, estando de acordo com as descrições de Pennington (1968), Reitz (1968), Cutter (1986), Marchiori (2000) e Kuera et al. (2002) para a espécie em estudo. A corola possui de 3 a $4 \mathrm{~mm}$ de altura e de 5 a $7 \mathrm{~mm}$ de largura. Os estames encontram-se soldados na base da flor, com anteras de coloração amarelo-ouro, extrorsas, rimosas, com 0,3 a $0,5 \mathrm{~mm}$ de altura por $1 \mathrm{~mm}$ de largura, e o filete de $0,1 \mathrm{~mm}$ de altura por 2,5 a $3 \mathrm{~mm}$ de largura, sendo de inserção dorsal (Figura 1E, F). Simetria floral *K5C5A5G(2-5) (Figura 1G).

\section{Morfologia do fruto}

A frutificação é abundante, porém irregular, ou seja, nem todas as árvores florescem todos os anos, ocorrendo o mesmo para C. oppositum, conforme Alencar (1994), o qual cita que a disponibilidade de água parece ser uma necessidade importante para a frutificação das sapotáceas, por possuírem frutos carnosos. A dispersão é zoocórica (mamalio, mirmeco e ornitocórica) durante o período de maio a novembro.

Durante a ontogênese dos frutos, foram observadas mudanças de forma, tamanho e cor (Figura 2A, B). O fruto maduro é constituído de uma baga quadrangular de coloração amarela, superfície lisa, brilhante, polpa fina, com pericarpo carnoso, 1 a 5 sementes, lóculos monospérmicos, cálice persistente, concordando com as descrições feitas por Beltrati et al. (1983). Mede de 1,5 a $3 \mathrm{~cm}$ de comprimento por $2 \mathrm{~cm}$ de largura (Figura 2C a F). Reitz (1968), na descrição que faz dessa espécie, cita apenas a largura dos frutos, que é de $1,5 \mathrm{~cm}$. 


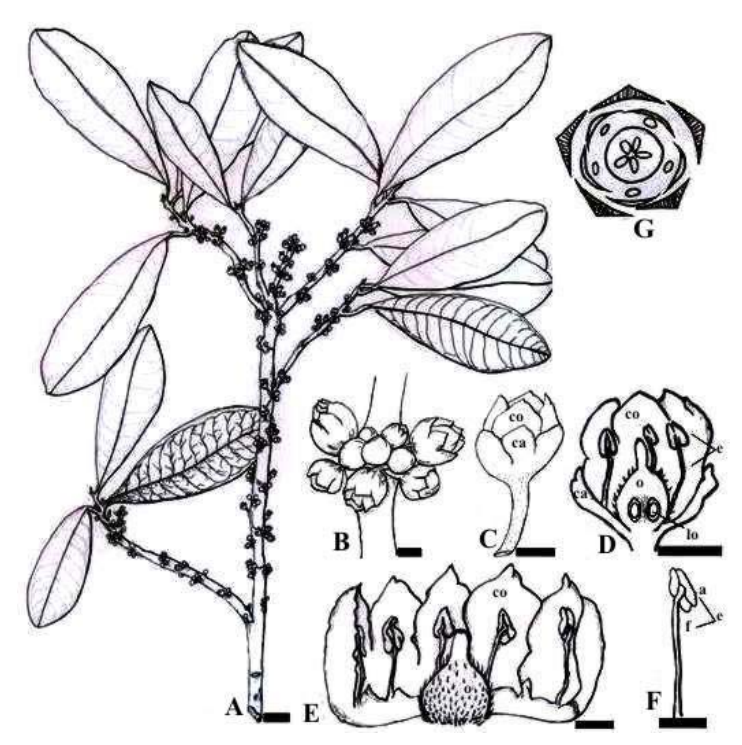

Figura 1. Flor: A - Ramo florido; B - Cacho com flores; C - Flor; D - Flor/corte longitudinal; E - Flor aberta; F - Estame; G - Diagrama floral; a - antera; ca - cálice; co - corola; e - estame; f - filete; lo - lóculo; o - ovário. Barra de escala: $1 \mathrm{~cm}$ para $1 \mathrm{~A} \mathrm{e} 0,2 \mathrm{~cm}$ para as demais.

Figure 1. Flower: A - Flowery branch; B - Racemes with flowers; C - Flower; D - Flower longitudinal section; E - Open flower; F - Stamen; G - Floral diagram. a - anther; ca - calyx; co - corolla; e stamen; f - filament; lo - loculo; - o - ovary). Bar of scale: $1 \mathrm{~cm}$ for $1 \mathrm{~A}$ and $0,2 \mathrm{~cm}$ for the other ones.
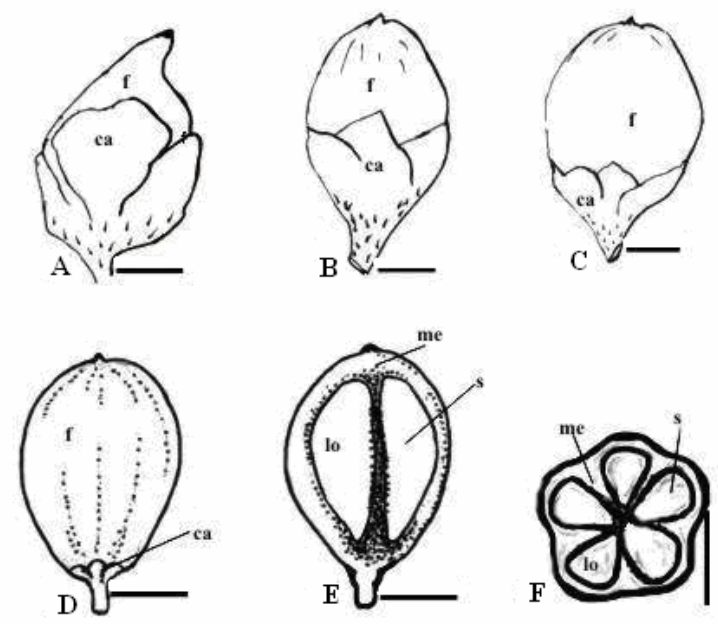

Figura 2. Fruto: $\mathrm{H}$ a $\mathrm{J}$ - Frutos em diferentes fases de desenvolvimento; $\mathrm{L}$ - Fruto maduro inteiro; $\mathrm{M}$ Fruto maduro/corte longitudinal; N - Fruto maduro/corte transversal; ca - cálice; $\mathrm{f}$ - fruto; lo lóculo; me - mesocarpo; s - semente. Barra de escala: $0,2 \mathrm{~cm}$ para $2 \mathrm{H}$ a J e $1 \mathrm{~cm}$ para as demais.

Figure 2. Fruit: $\mathrm{H}$ to $\mathrm{J}$ - Fruits in different phases of development; $\mathrm{L}$ - Entire mature fruit; $\mathrm{M}$ - Mature fruit longitudinal section; $\mathrm{N}$ - Mature fruit in cross section; ca - calyx; $\mathrm{f}$ - fruit; lo - locule; me mesocarp; $\mathrm{s}$ - seed. Bar of scale: $0,2 \mathrm{~cm}$ for $2 \mathrm{H}$ a $\mathrm{J}$ and $1 \mathrm{~cm}$ for the other ones. na tabela 1 .

As dimensões, desvio padrão e coeficiente de variação (C.V.) dos frutos podem ser observados 
Tabela 1. Dimensões dos frutos $(\mathrm{cm})$, desvio padrão e coeficiente de variação (C.V).

Table 1. Dimensions of the fruits $(\mathrm{cm})$ standard deviation and coefficient of variation (C.V.).

\begin{tabular}{lccccc}
\hline Dimensões (cm) & Máxima & Média & Mínima & Desvio padrão & C.V. (\%) \\
\hline Comprimento & 3,01 & 2,05 & 1,45 & 0,54 & 26,34 \\
Largura & 2,07 & 1,77 & 1,2 & 0,45 & 25,42 \\
Espessura & 2,85 & 1,62 & 1,08 & 0,35 & 21,60 \\
\hline
\end{tabular}

Observa-se, na figura 3, a quantidade de sementes por fruto, com uma média de 2,88 sementes/fruto, sendo a maior freqüência de 3 sementes por fruto, podendo haver variação, resultado este não descrito antes em outros trabalhos.

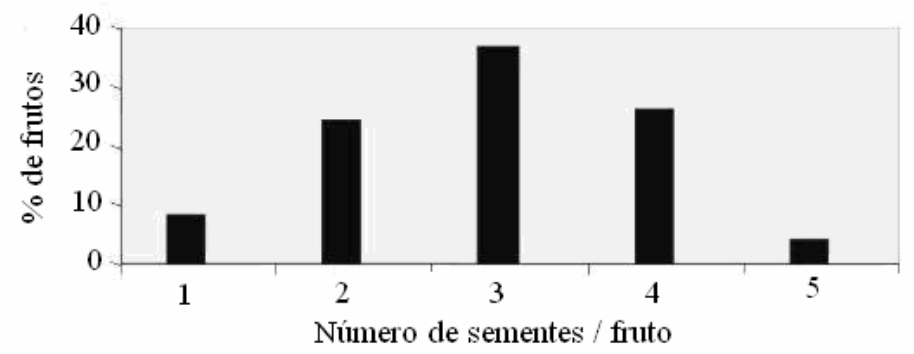

Figura 3. Quantidade de sementes por fruto.

Figure 3. Amount of seeds per fruit.

\section{Morfologia da semente}

Com aproximadamente três meses, observou-se que o embrião na fase esférica ou globular de desenvolvimento possui suspensor bastante longo. Aos quatro meses e meio, a organização dos dois cotilédones deu ao embrião a configuração de coração (cordiforme). Por volta do quinto mês de desenvolvimento, o alongamento do eixo do embrião levou a um estágio descrito como cotiledonar. Em ambas as fases, observou-se um endosperma uniforme, gelatinoso, de coloração branca cristalina circundando o embrião. Como observado para os frutos, as sementes de C. gonocarpum também apresentaram variações em suas dimensões, porém com coeficiente de variação inferior (Tabela 2).

Tabela 2. Dimensões das sementes $(\mathrm{cm})$, desvio padrão e coeficiente de variação (C.V.).

Table 2. Dimensions of the seeds (cm), standard deviation and coefficient of variation (C.V.).

\begin{tabular}{lccccc}
\hline Dimensões (cm) & Máxima & Média & Mínima & Desvio padrão & C.V. (\%) \\
\hline Comprimento & 2,1 & 1,67 & 1,2 & 0,36 & 21,56 \\
Largura & 0,95 & 0,79 & 0,6 & 0,08 & 10,13 \\
Espessura & 0,95 & 0,71 & 0,5 & 0,06 & 8,45 \\
\hline
\end{tabular}

Os dados morfométricos dos frutos e sementes, embora de valor taxonômico questionável, são utilizados por vários autores (BRAVATO, 1974; OLIVEIRA; BELTRATI, 1994; MELO; MENDONÇA; MENDES, 2004) e têm indiscutível valor ecológico, auxiliando na determinação da variabilidade da espécie, bem como no estudo do tipo de dispersão e dos agentes dispersores.

Externamente, a forma da semente madura é ovalada. Conforme a descrição de Longhi (1995), Pennington (1968), Reitz (1968), Beltrati et al. (1983), Van Roosmalen; Garcia (2000) e Kuera et al. (2002), a semente possui forma de meia-lua. O tegumento é de cor castanho-lustrosa, com cicatriz linear visível de coloração clara, circundando quase toda a extensão da semente (Figura 4A e B), a micrópila é apical e a calaza é indistinta (Figura 4B), característica da família, conforme Corner (1976). O suprimento vascular que penetra na região superior do hilo percorre uma curtíssima rafe, emitindo vários ramos póscalazais. Estes seguem pela anti-rafe e pelos flancos da semente, havendo um a cada lado do hilo e convergem para a região micropilar (Figura 4C), concordando com Beltrati et al. (1983).

Internamente, o endosperma é abundante, de coloração branca, transparente, oleoso, uniforme, circundando o embrião, axial, reto, espatulado, com cotilédones foliáceos grandes e de coloração branca, 
lisos, com nervuras visíveis e hipocótilo curto, cilíndrico e espesso (Figura 4D e E), descrições estas que concordam com Pennington (1968), Reitz (1968), Beltrati et al. (1983), Longhi (1995), Van Roosmalen (2000) e Kuera et al. (2002), com exceção do endosperma oleoso. Além desses dados, anotou-se o tamanho das sementes, as quais medem de 1,2 a $2,1 \mathrm{~cm}$ de comprimento por 0,6 a 0,95 cm de largura, conforme tabela 2, a qual discorda das descrições realizadas por Kuera et al. (2002), que cita sementes com largura de 1 a $2 \mathrm{~cm}$.
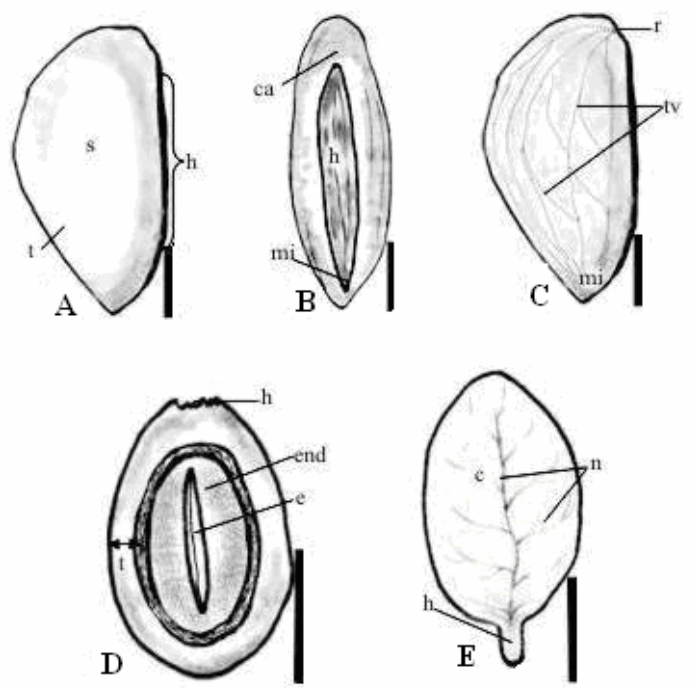

Figura 4. Semente e embrião: O e P - Semente inteira; Q - Corte longitudinal; R - Corte transversal; S Embrião; ca - calaza; c - cotilédone; e - embrião; end - endosperma; h - hilo; mi - micrópila; $\mathrm{n}$ nervuras; $\mathrm{t}$ - tegumento; tv - traço vascular; $\mathrm{r}$ - rafe; $\mathrm{s}$ - semente. Barra de escala: $0,5 \mathrm{~cm}$.

Figure 4. Seed and embryo: O and P - Entire seed; Q - Longitudinal section; R - Cros section; S Embryo; ca - chalaza; c - cotyledon; e - embryo; end - endosperm; h - hilum; mi - micropyle; $\mathrm{n}$ - veins; $\mathrm{t}$ - seed coat; $\mathrm{tv}$ - vessel traces; $\mathrm{r}$ - raphe; $\mathrm{s}$ - seed. Bar of scale: $0,5 \mathrm{~cm}$.

\section{Morfologia da germinação e plântulas}

A germinação das sementes de C. gonocarpum é epígea e as plântulas são do tipo fanerocotiledonar, com emergência curvada, semelhante ao observado por Carvalho; Muller (1998) em Pouteria caimito (Ruiz et Pavon) Radlk. e em Pouteria pachycarpa, citados por Cruz (2005). Os eventos da germinação podem ser visualizados na figura 5 .

A germinação inicia-se com a reidratação da semente, com o aumento do seu volume. A protrusão ocorre próximo ao hilo, entre o $15^{\circ}$ e o $20^{\circ}$ dia após a semeadura (Figura 5 - A). Inicialmente, a raiz primária cilíndrica, esbranquiçada, com coifa amarelada, se desenvolve rapidamente, engrossando e sofrendo afinamento, com dilatação na base. À medida que a raiz se alonga, adquire a coloração amarela, e após sete dias da germinação aparecem pêlos absorventes, esparsos (Figura 5 - B), de cor pérola e coifa castanha.

Com o alongamento da raiz primária, percebe-se a diferenciação do hipocótilo, brancoesverdeado, cilíndrico, espesso, longo, inicialmente verde claro e curvo, tornando-se reto e róseo à medida que ocorre o seu alongamento, coberto por pêlos simples, curtos, enquanto que o tegumento inicia o desprendimento 13 dias após a germinação (Figura 5 - C). Aos 19 dias, o tegumento desprende-se dos cotilédones, e estes iniciam a abertura horizontal, sendo foliáceos, inicialmente de coloração amarela, tornando-se verdes com o passar dos dias. Com nervuras evidentes, são obovados, opostos, ápice arredondado, base levemente truncada, visualizando-se, entre eles, o primeiro protofilo, de coloração verde-clara, aos 25 dias após a germinação (Figura 6).

No $31^{\circ}$ dia, a plântula está completamente formada, com raiz verde-clara de 6,5 a $8 \mathrm{~cm}$ de comprimento e raízes secundárias, finas, branco-amareladas. $\mathrm{O}$ epicótilo é verde-claro, cilíndrico, mede $0,7 \mathrm{~cm}$ de comprimento e possui a presença de cotilédones. A região do colo é delimitada por uma protuberância lateral de coloração verde-clara (Figura 6 - D). 

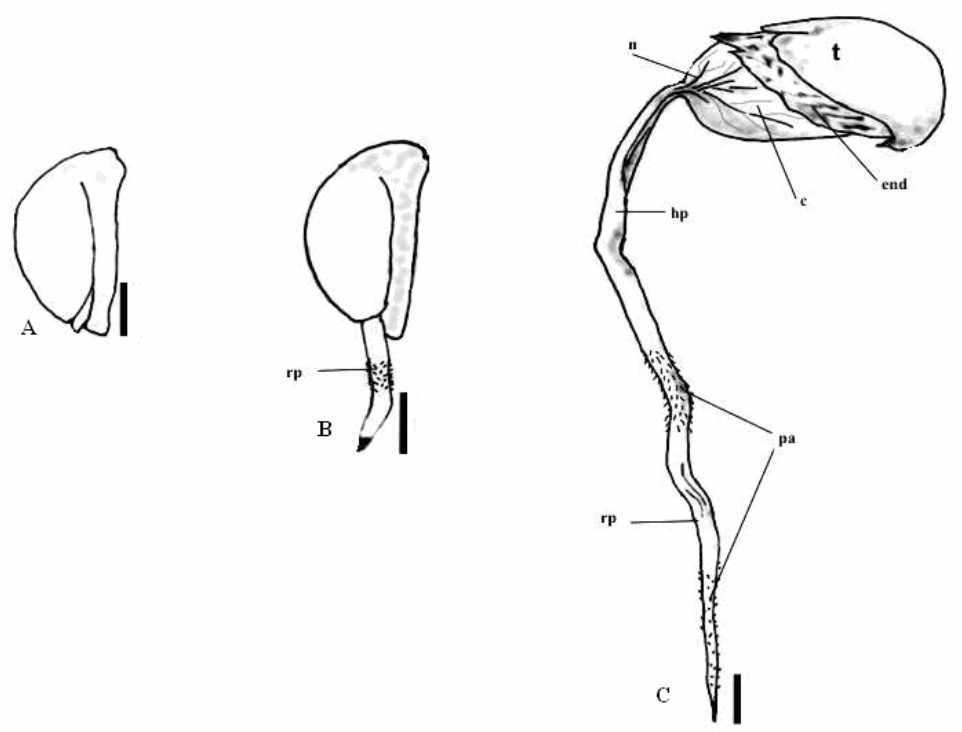

Figura 5. Germinação de C. gonocarpum. A - Emissão da radícula após o $15^{\circ}$ dia de semeadura; B - 7 dias de idade; C - 13 dias de idade; c - cotilédone; end - endosperma/fina camada restante; hp hipocótilo; $\mathrm{n}$ - nervuras; pa - pêlos absorventes; $\mathrm{rp}$ - raiz primária; $\mathrm{t}$ - tegumento. Barra de escala: $0,5 \mathrm{~cm}$.

Figure 5. Germination of C. gonocarpum. - Emission of radicule after the $15^{\circ}$ day of sowing; B - 7 days of age; $\mathrm{C}$ - 13 days of age; c - cotyledon; end - endosperm/fine remaining layer; hp - hypocotyl; $\mathrm{n}$ vessel elements; pa - root hair; rp - primary root; $\mathrm{t}$ - seed coat. Bar of scale: $0,5 \mathrm{~cm}$.

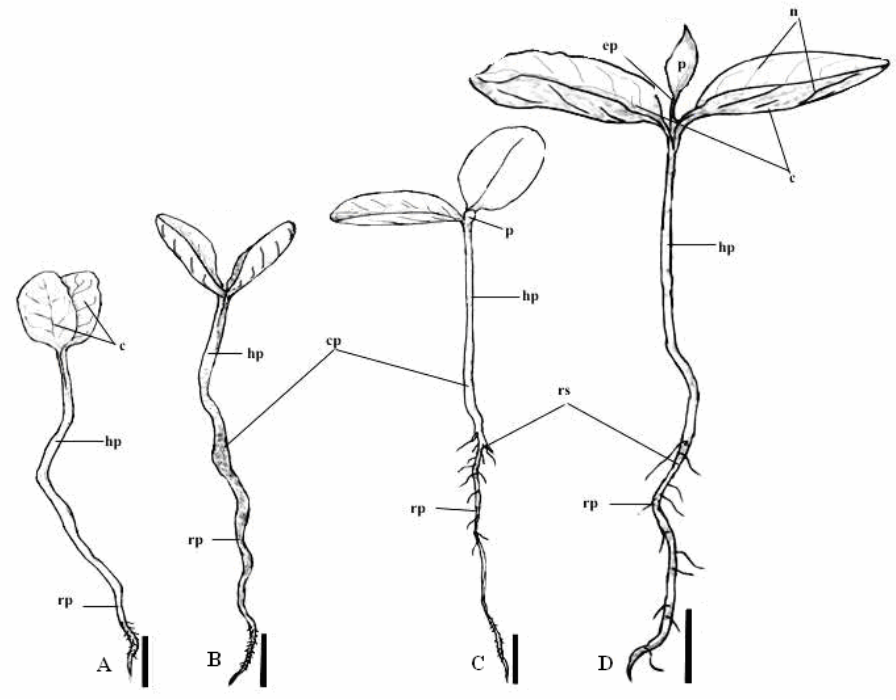

Figura 6. Estágios sucessivos de desenvolvimento de C. gonocarpum. A - 19 dias de idade; B - 23 dias de idade; C - 25 dias de idade; D - 31 dias de idade; c - cotilédone; co - coleto; ep - epicótilo; hp - hipocótilo; $\mathrm{n}$ - nervuras; $\mathrm{p}$ - protofilo; rp - raiz primária; rs - raiz secundária. Barra de escala: $0,8 \mathrm{~cm}$ para figura $\mathrm{D}$ e $2 \mathrm{~cm}$ para as demais.

Figure 6. Successive periods of development of C. gonocarpum. A - 19 days of age; B - 23 days of age; C - 25 days of age; D - 31 days of age; c - cotyledon; cp - collect; ep - epicotyl; hp - hypocotyl; $\mathrm{n}$ - veins; $\mathrm{p}$ - protophyll; rp - primary root; $\mathrm{rs}$ - secondary roots. Bar of scale: $0,8 \mathrm{~cm}$ for figure $\mathrm{D}$ and $2 \mathrm{~cm}$ for the other ones. 


\section{Análise física de sementes}

Das sementes que flutuaram, $9 \%$ estavam vazias. O peso de mil sementes foi de 2.625 unidades, com $47,16 \%$ de umidade e com coeficiente de variação de $4,19 \%$, ou seja, abaixo de $6 \%$, recomendado pela RAS (BRASIL, 1992), sendo que os resultados obtidos neste trabalho demonstram alta precisão. Conforme Lorenzi (2002), um quilograma de sementes de C. gonocarpum contém

aproximadamente 4.070 unidades, porém o autor não esclarece se realizou o teste de flutuação antes e nem a porcentagem de umidade, além de que não se dispõe de outras referências sobre o assunto.

Quanto à umidade das sementes de $C$. gonocarpum, observa-se na tabela 3 que a perda de água foi gradativa, conforme o passar dos dias, presumindo-se que as sementes dessa espécie são recalcitrantes, fenômeno freqüente em espécies arbóreas tropicais, conforme Neves (1994). Normalmente, sementes que pertencem a esse grupo possuem tamanho grande e elevado grau de umidade, por ocasião da dispersão (CHIN, 1988), que é outra característica observada em C. gonocarpum. Na família Sapotaceae, podem ser citadas espécies com sensibilidade ao dessecamento, tais como Micropholis cf. venulosa (CRUZ; CARVALHO, 2003) e Pouteria campechiana (MARCHIORI; MARTINS, 2002). Carvalho; Muller (1998) e Vásquez-Yanes; Aréchiga (1996) relatam o aparecimento de sementes recalcitrantes na família Sapotaceae.

Tabela 3. Percentagem de umidade em sementes $C$. gonocarpum.

Table 3. Percentage of humidity in seeds C. gonocarpum.

\begin{tabular}{ll}
\hline Material & Umidade (\%) \\
\hline Sementes provenientes de frutos verdes/amarelados, recém-colhidos. & 50 \\
Sementes maduras provenientes de frutos amarelos, recém-colhidos. & 47,16 \\
Sementes maduras após cinco dias de coleta. & 26,85 \\
Sementes maduras após sete dias de coleta. & 20,28 \\
\hline
\end{tabular}

Em observações visuais, constatou-se que o endosperma e o embrião se retraem rapidamente. Inicialmente, no momento da coleta, ambos encontram-se aparentemente sadios e preenchendo todo o interior da semente, o que, ao passar dos dias, resultou na redução do volume interno da semente, provavelmente devido à perda de umidade.

\section{Embebição de sementes}

As curvas referentes à embebição das sementes recém-colhidas, intactas e com corte na região calazal podem ser observadas nas figuras 7 e 8 . Ambas as sementes aumentaram seu peso durante o processo de embebição, indicando que houve absorção de água, a qual pode ter ocorrido através da micrópila, que é relativamente grande, conforme teste anatômico realizado por Felippi (2006). As sementes intactas absorveram água lentamente, havendo estabilização somente após 72 horas, enquanto que as sementes com corte tiveram absorção inicial alta, entre duas e sete horas, estabilizando-se a partir desse período. Em ambos os tratamentos, as sementes absorveram de 15 a $20 \%$ do peso em água. A absorção de água evidencia que as sementes não possuem dormência tegumentar.

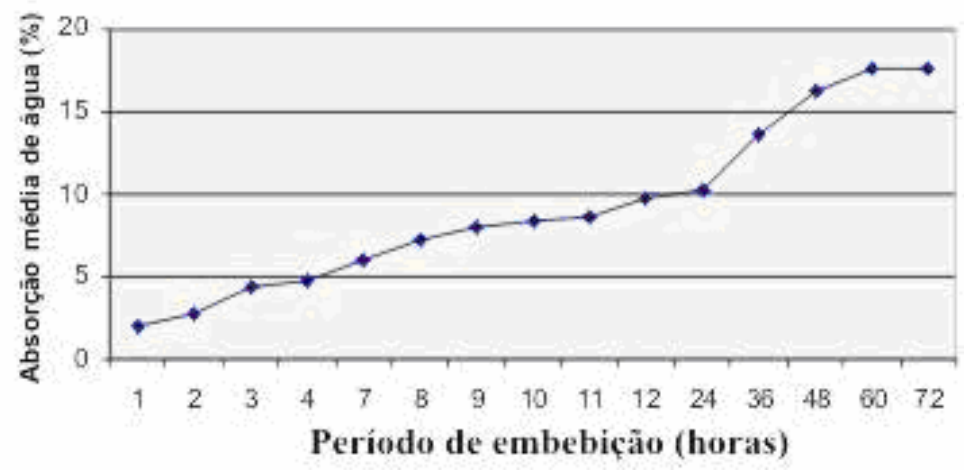

Figura 7. Curva de embebição das sementes intactas de C. gonocarpum.

Figure 7. Curve of soak of the intact seeds of $C$. gonocarpum. 


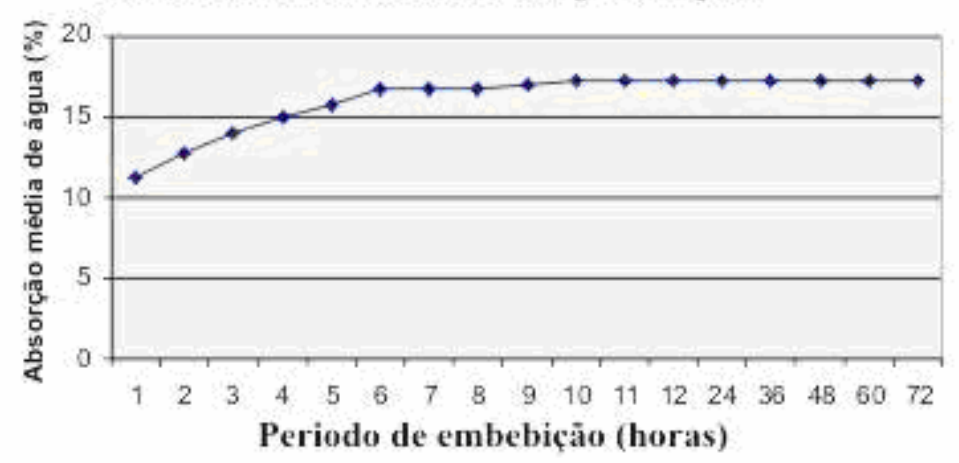

Figura 8. Curva de embebição das sementes de C. gonocarpum com corte na região calazal.

Figure 8. Curve of soak of the seeds of $C$. gonocarpum with cut in the chalazal region.

\section{Germinação}

O processo germinativo foi relativamente lento e desuniforme, iniciando-se a partir do $15^{\circ}$ dia após a semeadura, e estendeu-se até o $54^{\circ}$ dia. Em Sapotaceae, Villachina et al. (1996) também observaram que, para Pouteria macrophylla (Lam.) Eyma, a germinação iniciou-se no $24^{\circ}$ dia após a semeadura, e Carvalho; Muller (1998) observaram que em Pouteria caimito o início da germinação ocorreu a partir do $22^{\circ}$ dia.

Quanto à germinação lenta e desuniforme, Cruz (2005) verificou o mesmo para Pouteria pachycarpa, a qual iniciou a germinação somente 18 dias após a semeadura, atingindo a máxima de $86 \%$ aos 33 dias, estando em recipiente contendo areia e permanecendo em laboratório em condições ambientais. Resultados similares foram encontrados para Pouteria caimito por Villachina et al. (1996) e Carvalho et al. (1998), e em Pouteria sapota segundo Ricker et al. (2000).

De acordo com Lorenzi (2002), a viabilidade germinativa de C. gonocarpum persiste por mais de seis meses, sendo que a germinação é moderada, ocorrendo de 20 a 30 dias, em ambiente sombreado, no interior de recipientes individuais contendo substrato organo-argiloso.

O índice de velocidade de germinação (IVG) e a porcentagem (\%) final de sementes germinadas podem ser observados na tabela 4. O tempo necessário para que se obtivesse a máxima germinação foi de 25 dias. Após esse período, as sementes remanescentes apresentaram-se deterioradas e infestadas por patógenos, os quais não foram encaminhados para identificação, não sendo possível avaliar se ocorreu danos à germinação.

Através de análise estatística, pode-se observar que não houve diferença quanto à porcentagem de germinação entre os três tratamentos utilizados, conforme tabela 4.

Tabela 4. Porcentagem e índice de velocidade de germinação (IVG) de sementes de C. gonocarpum em três diferentes tratamentos.

Table 4. Percentage and index of speed germination (IVG) of seeds of C. gonocarpum in three different treatment.

\begin{tabular}{lcccc}
\hline Tratamentos & IVG & Germinação (\%) & Variância (S) & C.V. (\%) \\
\hline 5 min hipoclorito 3\% (PA) & 0,11 & 10,86 a* & 1,02 & 37,64 \\
$\begin{array}{l}\text { Lavagem com areia e água e 10 min } \\
\text { em hipoclorito comercial (2\%) }\end{array}$ & 0,03 & $3,43 \mathrm{a}$ & 0,33 & 38,37 \\
10 min hipoclorito 3\% (PA) & 0,05 & 5,71 a & 0,54 & 37,76 \\
\hline
\end{tabular}

*Médias seguidas da mesma letra na vertical não diferem estatisticamente entre si pelo Teste de Tukey a 5\%.

Não se pode afirmar que a baixa porcentagem de germinação pode ser atribuída à impermeabilidade do tegumento à água, fenômeno denominado de dormência tegumentar (MAYER; POLJAKOFF-MAYBER, 1982), já que houve absorção de água pelas sementes no teste de embebição. Esse fenômeno pode ser resultante da deposição de substâncias inibidoras da germinação localizadas na 
própria semente, e também pela rigidez do tegumento, podendo ocorrer um enfraquecimento do embrião, ou ainda pode estar associado à alta incidência de contaminação por fungos.

\section{CONCLUSÕES}

A antese é diurna e dura aproximadamente 24 horas, e a polinização é realizada por insetos no período de setembro a dezembro.

A dispersão da semente ocorre de maio a novembro por aves, mamíferos e insetos.

A semente tem forma ovalada e tegumento de cor castanha. Possui endosperma oleoso, embrião axial, espatulado, com cotilédones foliáceos.

A germinação é epígea e a plântula é caracterizada como fanerocotiledonar. O processo germinativo foi relativamente lento e desuniforme, porém observou-se a absorção de água pela semente, descartando-se a possibilidade de dormência tegumentar.

Devido às sementes possuírem alto grau de umidade e perda rápida de água, conclui-se que são recalcitrantes.

Há necessidade de maiores estudos para compreensão do processo germinativo de Chrysophyllum gonocarpum.

\section{AGRADECIMENTOS} mestrado.

À Universidade Federal do Paraná, pelo incentivo e apoio. À CAPES, pela concessão de bolsa de

\section{REFERÊNCIAS}

ABREU, D. C. A. de. Caracterização morfológica de frutos e sementes e germinação de Allophylus edulis (St. Hil). Radlk. e Drimys brasiliensis Miers. 91 f. Dissertação - (Mestrado em Engenharia Florestal) - Setor de Ciências Agrárias, Universidade Federal do Paraná, Curitiba, 2002.

AGAREZ, F. V.; RIZZINI, C. M.; PEREIRA, C. Botânica: taxonomia, morfologia e reprodução dos angiospermae: chaves para determinação das famílias. 2. ed. Rio de Janeiro: Âmbito Cultural, 1994. 256p.il.

ALCALAY, N.; AMARAL, D. M. I. Determinação de métodos de análises de espécies florestais que não constam nas regras de análise de sementes. Roessléria, Porto Alegre, v. 4, n. 1, p. 75-83. 1981.

ALENCAR, J. da C. Fenologia de cinco espécies arbóreas tropicais de Sapotaceae correlacionada a variáveis climáticas na reserva Ducke, Manaus, AM. Acta Amazônica, Manaus, v. 24, n. 3/4, p.161-181, 1994.

AMORIM, I. L. de. Morfologia de frutos, sementes, germinação, plântulas e mudas de espécies florestais da região de Lavaras - MG. 127 p. Dissertação (Mestrado em Ciências Florestais) Universidad Federal de Lavras, Lavras, 1996.

BARROSO, G. M. Sistemática de angiospermas do Brasil. São Paulo: EDUSP, 1978. v. 1, 255 p.

BARROSO, G. M.; MORIM, M. P.; PEIXOTO, A. L.; ICHASO, C. L. F. Frutos e sementes: morfologia aplicada à sistemática de dicotiledôneas. Viçosa: Universidade Federal de Viçosa, 1999. 443 p.

BELL, A. D. Plant form: an illustrated guide to flowering plant morphology. Oxford: Oxford University Press, $1991.341 \mathrm{p}$.

BELTRATI, C. M.; BARALDI, M. B. G.; PAGANO, S. N. Estudo morfoanatômico das sementes de Chrysophyllum gonocarpum (Mart. \& Eichl.) Engler (Sapotaceae). Naturalia, São Paulo, v. 8, p. 159167, 1983.

BRASIL. Ministério da Agricultura e Reforma Agrária. Regras para análises de sementes. Brasília, DF, 1992. $188 \mathrm{p}$. 
BRASIL. Ministério da Agricultura. DMPA-DPP. Levantamento de reconhecimento dos solos do Estado do Rio Grande do Sul. In-. Recife, 1973. 431 p. (Boletim Técnico, n. 30).

BRAVATO, M. Estudo morfológico de frutos e semillas de las Mimosoideae (Leguminosae) de Venezuela. Acta Botânica Venezuelica, Caracas, v. 9, n. 1-4, p. 317-361, 1974.

CARVAlHO, J. E. U.; MÜllER, C. H. Níveis de tolerância e letal de umidade em sementes de pupunheira, Bactris gasepaes. Revista Brasileira de Fruticultura, Cruz das Almas, v. 20, n. 3, p. 283289, 1998.

CHIN, H. F. Recalcitrant seeds: a status report. Rome: International Board for Genetic Resources, 1988. $28 \mathrm{p}$.

CORNER, E. J. H. The Seeds of Dicotyledons, London: Cambridge University Press, 1976.

CRUZ, D. E. Quantitative characteristics of fruits and seeds of Pouteria pachycarpa Pires - Sapotaceae. Revista Brasileira de Sementes, Brasília, DF, v. 27, n. 2. p. 159-164, 2005.

CRUZ, E. D.; CARVALHO, J. E. U. de. Biometria de Frutos e Sementes e Germinação de Curupixá (Micropholis cf. venulosa Mart. \& Eichler - Sapotaceae). Acta Amazônica, Manaus, v. 33, n. 3, p. 389398, 2003.

CUTTER, E. G. Anatomia vegetal: experimentos e interpretações: segunda parte: órgãos:. São Paulo: Roca, 1986. 336 p.

DONADIO, N. M. M.; DEMATÊ, M. E. S. P. Morfologia de frutos, sementes e plântulas de canafistula (Peltophorum dubium (Spreng) Taub.) e jacarandá-da-Bahia (Dalbergia nigra (Vell.) Fr. All. Ex Benth.) Fabaceae. Revista Brasileira de Sementes, Brasília, DF, v. 22, n. 1, p. 64-73, 2000.

FELICIANO, A. L. P. Estudo da germinação de sementes e desenvolvimento da muda, acompanhado de descrições morfológicas de 10 espécies arbóreas ocorrentes no semi-árido nordestino. Dissertação (Mestrado) - Universidade Federal de Viçosa, Viçosa, MG, 1989.

FELIPPI, M. Morfologia da flor, do fruto e da plântula: ontogênese e germinação da semente de Chrysophyllum gonocarpum (Mart. \& Eichl.) Engl. 61 f. Dissertação (Mestrado em Engenharia Florestal). - Setor de Ciências Agrárias, Universidade Federal do Paraná, Curitiba, 2006.

KUERA, N. Y. M.; LOPEZ, J. A.; LITTLE JR., E. L.; RITZ, G. F.; ROMBOLD, J. S.; HAHN, W. J. Arboles comues del Paraguay. Asunción: Universidad Nacional de Asunción/Facultad de Ciencias Agrarias, 2002. 458 p.

KUNIYOSHI, Y. S. Morfologia da semente e da germinação de 25 espécies arbóreas de uma floresta com araucária. 232 f. Dissertação (Mestrado em Engenharia Florestal). - Setor de Ciências Agrárias, Universidade Federal do Paraná, Curitiba, 1983.

LONGHI, R. A. Livro das árvores: árvores e Arvoretas do Sul. Porto Alegre: L \& PM, 1995.

LOPES, R. C. Ebenaceae Vent. do Estado do Rio de Janeiro. Rodriguésia, Rio de Janeiro, v. 50, n. 76/77, p. 85-107, 1999.

LORENZI, H. Árvores brasileiras: manual de identificação e cultivo de plantas arbóreas nativas do Brasil. Nova Odessa: Plantarum, 2002.

MAYER, A. M.; POLYKOFF-MAYBER, A. The germination of seeds. 3. ed. New York: Pergamon, 1982. $211 \mathrm{p}$.

MARCHIORI, J. N. C. Dendrologia das Angiospermas: das bixáceas às rosáceas. Santa Maria: Editora UFSM, 2000. 240 p.

MARCHIORI, T. T.; MARTINS, A. B. G. Efeito do armazenamento na porcentagem de germinação de sementes de caninstel (Pouteria campechiana). In: CONGRESSO BRASILEIRO DE FRUTICULTURA, 17, 2002, Belém. Anais... Belém: SBF, 2002. 
MATOS, V. P.; AZEREDO, G. A. de; GONCALVES, E. P.; SILVA, A. da; RODRIGUES, L. de F. Sementes de Sapoti (Achras sapota L.): dormência e emergência. Pesquisa Agropecuária Tropical, Goiania, v. 33, n. 2, p.79-82, 2003.

MARIOT, A.; MANTOVANI, A.; REIS, M. S. Uso e conservação de Piper cernuum Vell (Piperaceae) na Mata Atlântica: I. Fenologia reprodutiva e dispersão de sementes. Revista Brasileira de Plantas Medicinais, Botucatu, v. 5, n. 2, p. 1-10, 2003.

MELO, M. da G. G.; MENDONÇA, M. S. de; MENDES, A. M. da S. Análise morfológica de sementes, germinação e plântulas de jatobá (Hymenaea intermedia Ducke var. adenotricha (Ducke) Lee \& Lang.) (Leguminosae-caesalpinioideae). Acta Amazônica, Manaus, v. 34, n. 1, p. 9-14, 2004.

MISSIO, E. Proposta conceitual de zoneamento ecológico e econômico para o município de Frederico Westphalen/ RS. 181 f. Tese (Doutorado em Ecologia e Recursos Naturais) - Setor de Ciências Biológicas, Universidade Federal de São Carlos, São Carlos, SP, 2003.

MORELLATO, L. P. As estações do ano na floresta. In: LEITÃO FILHO, H. F.; MORELLATO, L. P. C. (Orgs.). Ecologia e preservação de uma floresta tropical urbana: Reserva de Santa Genebra. Campinas: UNICAMP, 1995. p. 187-192.

NAKAGAWA, J. Testes de vigor baseados na avaliação das plântulas. In: VIEIRA, R. D.; CARVALHO, N. M. Testes de vigor em sementes. Jaboticabal: FUNEP, 1994. p. 49-86.

NEVES, C. S. V. J. Sementes recalcitrantes: revisão de literatura. Pesquisa Agropecuária Brasileira, Rio de Janeiro, v. 29, n. 9, p. 1459-1467, 1994.

OLIVEIRA, E. de C. Morfologia de plântulas florestais. In: AGUIAR, I.B. de; PIÑA-RODRIGUES, F. C. M. Sementes Florestais Tropicais. Brasília, DF: ABRATES, 1993. p.175-214.

OLIVEIRA, D. M. T. de; BELTRATI, C. M. Morfologia e anatomia dos frutos e sementes de Inga fagifolia Willd. (Fabaceae: Mimosoideae). Revista Brasileira de Biologia, Rio de Janeiro, v. 54, n. 1, p. 91-100, 1994.

PENNINGTON, T. D. Sapotaceae. New York: Organization for flora Neotropica by the New York Botanical Garden, 1968. (Flora Neotropica, Monograph, n. 52).

PORTO ALEGRE. . Secretaria Estadual do Meio Ambiente. Inventário florestal contínuo do Rio Grande do Sul. Porto Alegre: SEMA; Santa Maria: Universidade Federal de Santa Maria, 2001.

REITZ, P. R. Sapotáceas. Itajaí: Herbário Barbosa Rodrigues, 1968. (Flora Ilustrada Catarinense. Parte I: as plantas).

RICKER, M.; SIEBE, C.; SANCHEZ B. S.; SHIMADA, K.; LARSAN, B. C.; MARTINEZ-RAMOS, M.; MONTAGNINI, F. Optimizing seedling management: Pouteria sapota, Diospyros digyna and Cedrela odorata in a Mexican rainforest. Forest Ecology and Management, Amsterdam, v. 139, n. 1/3, p. 63-77, 2000.

RODERJAN, C. V. Morfologia do estágio juvenil de 24 espécies arbóreas de uma floresta com Araucária. 148 p. Dissertação (Mestrado em Engenharia Florestal) - Setor de Ciências Agrárias, Universidade Federal do Paraná, Curitiba, 1983.

SOUZA, L. A. de. Morfologia e anatomia vegetal: célula, tecidos, órgãos e plântula. Ponta Grossa: UEPG, 2003. 259p.

SOUZA, L. A. de; MOSCHETA, I. S.; MOURÃO, K. S. M.; ROSA, S. M. Morfo-anatomia da flor de Guarea kunthiana A. Juss. e de Guarea macrophylla Vahl. (Meliaceae). Acta Scientiarum. Maringá, v. 24, n. 2, p. 591-600,2002.

WEBERLING, F. Morphology of flowers and inflorescences. London: Cambridge University Press, 1989. 
VAN ROOSMAlen, M. G. M.; GARCIA O. M. da C. G. Fruits of the Amazonian Forest. Part II: Sapotaceae. Acta Amazônica, Manaus, v. 30, n. 2, p. 187-290, 2000.

VÁZQUEZ-YANES, C.; ARÉCHIGA, M. R. Ex situ conservation of tropical rain forest seed: problems and perspectives. Interciência: una revista de ciencia y tecnologia para el desarrollo, Caracas, v.. 21, n. 5, p. 293-298, 1996.

VIDAL, W. N.; VIDAL M. R. R. Botânica: organografia: quadros sinóticos ilustrados de fanerógamos. 4. ed. Viçosa: UFV, 2000. 124 p.

VILlACHINA, H.; CARVALHO, J. E. U. de; MUllER, C. H.; DIAZ, C.; ALMANZA, M. Frutales y hortalizas promisorios de la Amazônia. Lima: Tratado de Cooperacion Amazônica, Secretaria ProTempore, 1996. 367 p. 